\title{
Implementasi Telegram Bot untuk Monitoring Mikrotik Router
}

\author{
The Implementation of Bot Telegram for Monitoring Microtic Router \\ Dimara Kusuma Hakim ${ }^{1}$, Septian Adi Nugroho ${ }^{2}$ \\ ${ }^{1,2}$ Teknik Informatika, Fakultas, Universitas Muhammadiyah Purwokerto \\ Jl. Raya Dukuh Waluh, Purwokerto 53182 \\ 1imarakusumahakim@gmail.com \\ ${ }^{2}$ septian.opush@gmail.com
}

\begin{abstract}
ABSTRAK
Smartphone muncul sebagai alat praktis untuk digunakan dalam aktivitas harian dan acara besar termasuk interaksi sosial. Hal itu dikarenakan smartphone memberikan akses pengguna untuk melakukan layanan dan sumberdaya yang kuat melalui media yang kecil. Salah satu layanan yang terdapat pada Smartphone adalah adanya fasilitas instant messenger yang tentunya dapat memberikan kemudahan dalam komunikasi jarak jauh. Berbagai aplikasi instant messenger tersedia pada smartphone seperti salah satunya telegram. Di suatu instansi terkadang memiliki masalah dengan mikrotik router, terutama masalah pengawasan, sementara mikrotik router berakibat fatal jika terjadi ganguan dan admin atau teknisi yang terkadang memiliki jadwal diluar sehingga mereka membutuhkan cara cepat untuk mendapatkan informasi kondisi mikrotik router yang ada pada ruangan. Berdasaran masalah tersebut, maka dimungkinkan untuk membuat sebuah Telegram Bot untuk monitoring miktorik router. Mengingat belum adanya sebuah Telegram Bot pada untuk monitoring mikrotik router pada Cv.Infomedia Technology. Bot telegram sebagai jembatan antara mikrotik dan smartphone, mikrotik dan smartphone harus terhubung dengan koneksi internet agar dapat mengirim notifikasi ke smartphone. notifikasi dikirim dalam bentuk informasi dari mikrotik dan terintegrasi ke aplikasi telegram. Informasi yang diberikan terdiri dari konektivitas jaringan, user hotspot login atau logout dan kondisi mikrotik. Notifikasi langsung masuk ke akun telegram admin atau teknisi.
\end{abstract}

Kata Kunci: Mikrotik Router, Telegram, Telegram bot.

\begin{abstract}
Smartphones appear as practical tools for use in daily activities and large events including social interactions. That's because smartphones provide users access to services and strong resources through small media. One of the services found on smartphones is the instant messenger facility which can certainly provide convenience in long distance communication. Various instant messenger applications are available on smartphones such as telegram. In an agency sometimes has problems with the proxy router, especially surveillance problems, while the proxy router is fatal if there is interference and the admin or technician who sometimes has a schedule outside so they need a quick way to get information on the router microtic condition in the room. Based on these problems, it is possible to create a Telegram Bot for monitoring microtic routers. Given the lack of a Telegram Bot for monitoring routers in Cv.Infomedia Technology. Telegram bot as a bridge between the proxy and smartphone, the proxy and smartphone must be connected to an internet connection in order to send notifications to the smartphone. notifications are sent in the form of information from the proxy and integrated into the telegram application. The information provided consists of network
\end{abstract}


connectivity, user hotspot login or logout and microtic conditions. Notifications go directly to the admin or technician telegram account.

Keywords: Mikrotik Router, Telegram, Telegram bot.

\section{PENDAHULUAN}

Smartphone muncul sebagai alat praktis untuk digunakan dalam aktivitas harian dan acara besar termasuk interaksi sosial. Hal itu dikarenakan smartphone memberikan akses pengguna untuk melakukan layanan dan sumberdaya yang kuat melalui media yang kecil, karena smartphone mampu memberikan kemudahan bagi penggunanya guna mendukung pekerjaan serta kegiatan sehari-hari. Dengan smartphone, manusia mampu mendapatkan informasi secara cepat dari satu tempat ke tempat yang lain walaupun dengan jarak yang berjauhan (Do, T. M. T., \& Gatica-Perez, D., 2013).

Salah satu layanan yang terdapat pada Smartphone adalah adanya fasilitas instant messenger yang tentunya dapat memberikan kemudahan dalam komunikasi jarak jauh. Berbagai aplikasi instant messenger tersedia pada smartphone seperti salah satunya telegram.

$\mathrm{CV}$. Infomedia adalah sebuah perusahaan yang bergerak pada bidang layanan jasa pembuatan program, aplikasi dan pembuatan webserver yang tentunya membutuhkan koneksi internet. Konfigurasi Koneksi internet pada Cv.infomedia mengunakan mikrotik router. Mikrotik router berfungsi sebagai pembagi koneksi internet ke perangkat lain dan juga sebagai hotspot.

Mikrotik Router pada CV. Infomedia memiliki masalah terutama masalah pengawasan seperti koneksi terputus secara mendadak, user hotspot login kedalam jaringan dan kondisi fisik mikrotik yang akan berakibat fatal apabila tidak diawasi secara rutin dan admin atau teknisi yang terkadang memiliki jadwal diluar sehingga mereka membutuhkan cara cepat untuk mendapatkan informasi kondisi mikrotik router yang ada pada Cv.Infomedia.

Berdasaran masalah tersebut, maka CV. Infomedia membutuhkan sebuah Telegram Bot untuk monitoring miktorik router yang dapat memberikan layanan informasi ketika koneksi terputus secara mendadak, user hotspot login kedalam jaringan dan kondisi fisik mikrotik untuk admin maupun teknisi yang rata-rata mempunyai smartphone. Hasil akhir penelitian ini dapat memberikan kemudahan dalam penerimaan informasi ketika koneksi terputus secara mendadak, user hotspot login kedalam jaringan dan kondisi fisik mikrotik bagi admin maupun teknisi CV. Infomedia.

\section{METODE}

Telegram adalah sebuah aplikasi yang memungkinkan pengguna atau user untuk mengirim pesan dengan cepat dan aman, selain itu Telegram sangat ringan, mudah dan gratis. Telegram dapat digunakan pada smartphone, tablet dan bahkan komputer. Telegram untuk platform iOS diluncurkan pada tanggal 14 Agustus 2013 (Telegram Team-1, 2015).

Bot Telegram merupakan akun khusus yang tidak memerlukan nomor telepon tambahan untuk didaftarkan ke Server Telegram. Akun ini berfungsi sebagai antarmuka antara kode program dengan server Telegram. Telegram merupakan salah satu aplikasi yang mendukung adanya bot ini. Dengan adanya bot ini dapat memudahkan pengguna membuat semacam aplikasi chatting (Telegram Team-2, 2015). 
Mikrotik adalah router canggih berbasis sistem operasi Linux. Alat ini digunakan untuk berbagai keperluan jaringan komputer, mulai dari ruting dinamis, hotspot, firewall, VPN, DHCP, DNS Cache, Web Proxy, dan beberapa fungsi lainnya. Karena penggunaanya yang sangat mudah, beberapa admin menyebut Mikrotik sebagai perangkat surganya para admin. Produk mikrotik terdiri dari berbagai versi, mulai dari router indoor, wireless router indoor/outdoor, embedded $2,4 \mathrm{GHz}$ atau $5, \mathrm{x} \mathrm{GHz}$, antena indoor/outdoor, dan lain-lain (Hardana \& Irvantino, I., 2014).

Jenis penelitian ini yang digunakan adalah jenis penelitian pengembangan sistem dimana bertujuan untuk mendapatkan hasil efektif dan efisien yang akan dicapai. metode penelitian metode air terjun (Waterfall method) (Sommerville, 2011).

\section{A. Analisis Kebutuhan}

Analisis kebutuhan terhadap sistem yang dibangun dapat digambarkan untuk menunjukan spesifikasi yang dibutuhkan. Berikut hasil analisis spesifikasi kebutuhan pada Tabel 1.

Tabel 1. Analisa Spesifikasi Kebutuhan

\begin{tabular}{|c|c|}
\hline No & Deskripsi \\
\hline \multirow[t]{3}{*}{1} & $\begin{array}{l}\text { Sistem harus menyediakan informasi jika terjadi ganguan pada jaringan mikrotik } \\
\text { dan juga ketika jaringan kembali normal kepada Admin atau Teknisi. } \\
\text { Spesifikasi Kebutuhan : }\end{array}$ \\
\hline & $\begin{array}{l}\text { 1. Sistem harus menyediakan informasi apabila koneksi jaringan DOWN } \\
\text { (request time out) }\end{array}$ \\
\hline & $\begin{array}{l}\text { 2. Sistem harus menyediakan informasi apabila koneksi jaringan } U P \text { atau } \\
\text { kembali normal. }\end{array}$ \\
\hline \multirow[t]{3}{*}{2.} & $\begin{array}{l}\text { Sistem harus menyediakan informasi jika ada user hotspot yang sudah terdaftar di } \\
\text { mikrotik melakukan login/logout kepada Admin atau Teknisi } \\
\text { Spesifikasi Kebutuhan: }\end{array}$ \\
\hline & $\begin{array}{l}\text { 1. Sistem harus menyediakan informasi alamat ip dan nama user yang login } \\
\text { ke dalam jaringan hotspot }\end{array}$ \\
\hline & $\begin{array}{l}\text { 2. Sistem harus menyediakan informasi alamat ip dan nama user yang logout } \\
\text { ke dalam jaringan hotspot }\end{array}$ \\
\hline \multirow[t]{4}{*}{3.} & $\begin{array}{l}\text { Sistem harus menyediakan informasi kondisi mikrotik kepada Admin atau Teknisi. } \\
\text { Spesifikasi Kebutuhan : }\end{array}$ \\
\hline & $\begin{array}{l}\text { 1. Sistem harus dapat menyediakan informasi berapa lama mikrotik menyala, } \\
\text { pengunaan kapasitas ram, pengunaan kapasitas hdd dan berapa persen } \\
\text { kinerja mikrotik. }\end{array}$ \\
\hline & 2. Sistem harus dapat menyediakan informasi kecepatan koneksi internet. \\
\hline & 3. Sistem harus dapat menyediakan informasi jumlah user hospot aktif. \\
\hline
\end{tabular}

\section{B. Rancangan Topologi Jaringan}

Terdapat 2 komponen hardware yaitu 1 PC dan 1 Mikrotik yang terhubung dengan Internet. PC 1 berperan sebagai client yang terhubung ke Mikrotik. Router Mikrotik berfungsi sebagai penghubung dari PC ke Internet, sebagai Hotspot dan juga sebagai tempat jalanya program yang akan dibangun, seperti pada Gambar 1. 


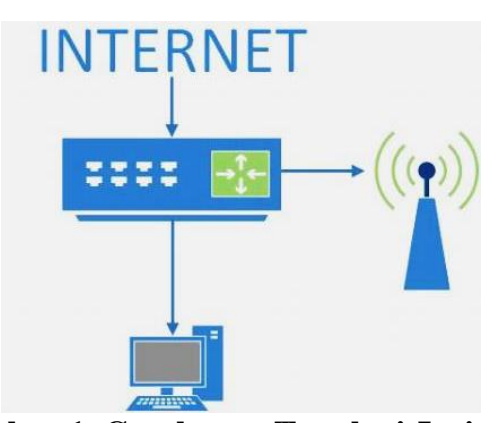

Gambar 1. Gambaran Topologi Jaringan

\section{Design Struktur Program}

Telegram bot server sebagai jembatan penghubung antara mikroti dan smarphone, smartphone harus terhubung dengan internet untuk bisa mendaptkan pesan notifikasi dan mikrotik harus terhubung dengan internet untuk bisa mengirim pesan notifikasi seperti pada Gambar 2.

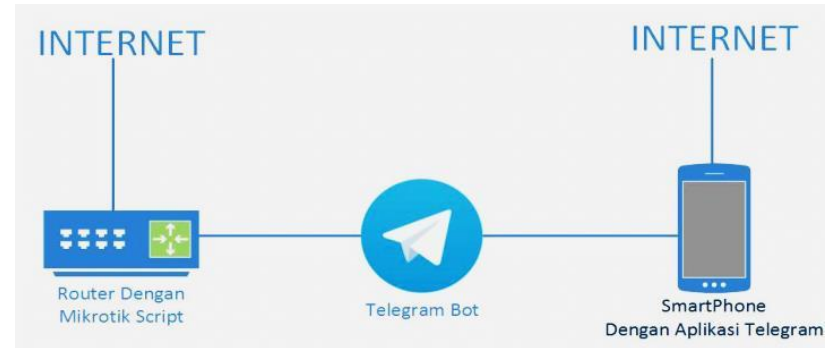

Gambar 2. Design Dasar Struktur Program

\section{Design Struktur Bot Monitoring Jaringan}

Telegram bot server sebagai jembatan penghubung antara mikroti dan smarphone untuk mengirim notifikasi ketika terjadi ganguan jaringan (Request time out) dan juga ketika jaringan sudah kembali normal seperti pada Gambar 3.

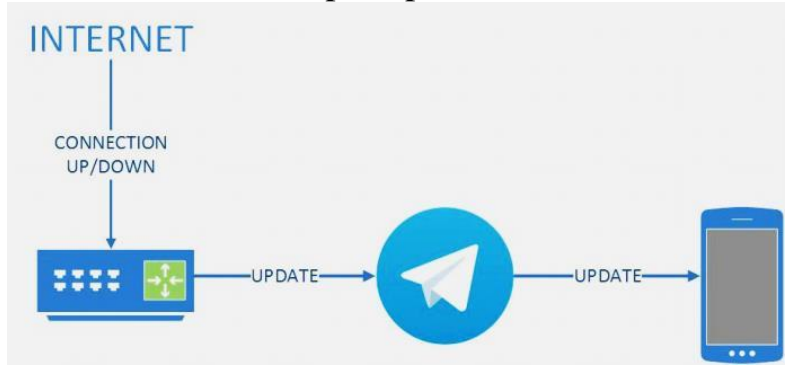

Gambar 3. Design Struktur Bot Monitoring Jaringan

\section{E. Design Struktur Bot Monitoring User Hotspot}

Telegram bot server sebagai jembatan penghubung antara mikroti dan smarphone untuk mengirim notifikasi ketika ada user hotspot yang sudah terdaftar dimikrotik melukan login kejaringan dan juga ketika user hotspot logout dari jaringan hotspot seperti pada Gambar 4. 


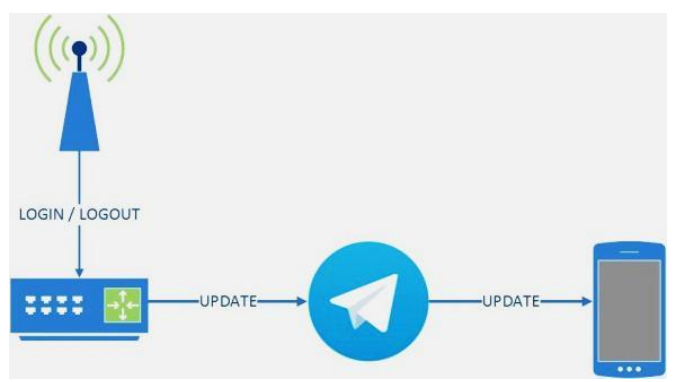

Gambar 4. Design Struktur Bot Monitoring User Hotspot

\section{F. Design Struktur Bot Monitoring Kondisi Mikrotik}

Telegram bot server sebagai jembatan penghubung antara smartphone dan mikrotik, smartphone melakukan request melalui Telegram server sebagai jembatan penghubung kemudian Telegram server menjalankan script yang di dalam mikrotik dan bot server memberikan update dari hasil request ke aplikasi telegram seperti pada Gambar 5.

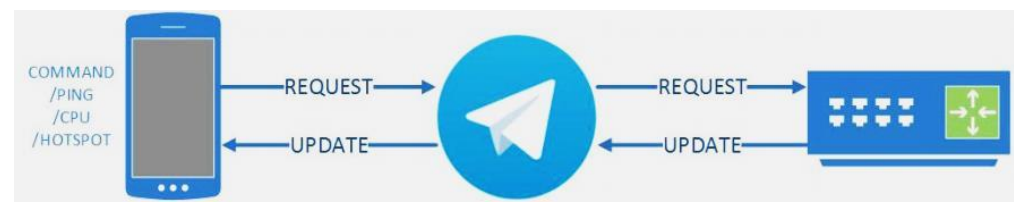

Gambar 5. Design Struktur Bot Monitoring Kondisi Mikrotik

\section{HASIL DAN PEMBAHASAN}

\section{A. Bot Monitoring Jaringan}

Bot akan otomatis berjalan apabila terjadi ganguan jaringan atau (Request time out) secara otomatis mengirim notifikasi pesan berisi ip address, waktu dan status koneksi sedang down ke aplikasi telegram dan Bot akan otomatis berjalan Jika jaringan sudah terhubung kembali secara otomatis mengirim notifikasi pesan berisi ip address, waktu dan status koneksi sedang up ke aplikasi telegram seperti pada Gambar 6.

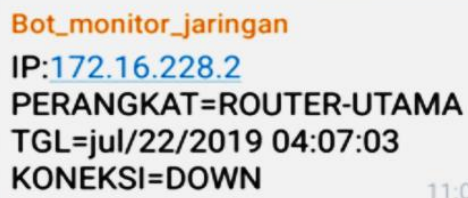

Gambar 6. Hasil Bot Monitoring Jaringan

\section{B. Bot Monitoring User Hotspot}

Jika ada user hotspot yang sudah terdaftar melakukan login bot akan otomatis berjalan dan ngirimkan notifikasi berisi pesan nama user dan ip address melakukan login dan Jika ada user hotspot logout bot akan otomatis berjalan dan ngirimkan notifikasi berisi pesan nama user dan ip address melakukan logout seperti pada Gambar 7.

\section{Bot_user_hospot}

LOGIN admin 192.168.1.251
Bot_user_hospot

LOGOUT admin 192.168.1.251

Gambar 7. Hasil Bot Monitoring User Hotspot 


\section{Bot Monitoring Kondisi Mikrotik}

Bot monitoring kondisi mikrotik memiliki beberapa comand seperti pada Gambar 8.

\begin{tabular}{|c|c|c|}
\hline /ping@Remote_mikrotik_bot 1241 v & /cpu@Remote_mikrotik_bot $11.21 \mathrm{~J} /$ & /hotspot@Remote mikrotik bot \\
\hline Botremotmikrotik & Botremotmikrotik & \\
\hline $\begin{array}{l}\text { ROUTER: ROUTER-UTAMA } \\
\text { TGL: jan/02/1970 02:10:22 } \\
\text { TEST PING : } 8.8 .8 .8 \\
\text { SPEED : } 23 m s \text { - packet loss: } 0 \%\end{array}$ & $\begin{array}{l}\text { ROUTER: ROUTER-UTAMA } \\
\text { MENYALA: 00:35:03JAM } \\
\text { CPU: } 6 \% \\
\text { RAM: } 25 \mathrm{M} / 128 \mathrm{M} \\
\text { HDD: } 17 \mathrm{M} / 128 \mathrm{M}\end{array}$ & $\begin{array}{l}\text { Bot_remot_mikrotik } \\
\text { Router Id: ROUTER-UTAMA } \\
\text { Hotspot users: } 1 \text { online }\end{array}$ \\
\hline
\end{tabular}

Gambar 8. Hasil dari semua Command

- /Ping ini menampilkan informasi time koneksi dan packet loss pada jaringan mikrotik

- /Cpu ini menampilkan informasi lama waktu mikrotik dihidupkan, berapa persen kerja Cpu pada mikrotik, Ram yang digunakan di mikrotik dan kapasitas Hdd yang digunakan di mikrotik

- /Hotspot ini menampilkan informasi jumlah user aktif pada jaringan hotspot mikrotik

\section{Pengujian}

Pengujian Fungsi Monitoring konektifitas jaringan down atau terputus dilakukan dengan membuat firewall drop ping atau pemblokiran ping dengan tujuan jika ip melakukan ping maka akan otomatis terputus (request time out), lalu untuk pengujian Fungsi Monitoring konektifitas jaringan up dengan melakukan disable firewall drop ping tersebut seperti pada Tabel 2.

Tabel 2. Pengujian Fungsi Monitoring konektifitas jaringan

\begin{tabular}{llll}
\hline No & Pengujian & Output & Status \\
\hline 1 & $\begin{array}{l}\text { Melakukan pemutusan koneksi } \\
\text { jaringan dengan firewall drop ping } \\
\text { ip tujuan agar menyebabkan RTO } \\
\text { (request time out) }\end{array}$ & $\begin{array}{l}\text { Tampil notifikasi setatus koneksi } \\
\text { down di group telegram }\end{array}$ & Berhasil \\
& $\begin{array}{l}\text { Melakukan perbaikan koneksi } \\
\text { jaringan dengan disable firewall } \\
\text { drop ping. }\end{array}$ & $\begin{array}{l}\text { Tampil notifikasi status koneksi } \\
\text { sedang } \text { up di group telegram }\end{array}$ & Berhasil \\
& & & \\
\hline
\end{tabular}

Pengujian dilakukan dengan melakukan login dengan username dan password kedalam hotspot dan melakukan logout dari jaringan hotspot seperti pada Tabel 3.

Tabel 3. Pengujian Fungsi Monitoring konektifitas jaringan

\begin{tabular}{llll}
\hline No & Pengujian & Output & Status \\
\hline 1 & $\begin{array}{l}\text { Melakukan login kedalam hotspot } \\
\text { dengan memasukan } \text { username dan } \\
\text { password }\end{array}$ & $\begin{array}{l}\text { Tampil notifikasi nama user } \\
\text { dan ip user login }\end{array}$ & Berhasil \\
2 & Melakukan logout dari hotspot. & $\begin{array}{l}\text { Tampil notifikasi nama user } \\
\text { dan ip user logout }\end{array}$ & Berhasil \\
\hline
\end{tabular}

Pengujian dilakukan dengan melakaukan request pada semua command yaitu /cpu, /ping dan /hotspot apakah respon atau notifikasi sesuai dengan apa yang diinginkan, seperti pada Tabel 4. 
Tabel 4. Pengujian Fungsi Monitoring Kondisi Mikrotik

\begin{tabular}{|c|c|c|c|}
\hline No & Pengujian & Output & Status \\
\hline 1 & $\begin{array}{l}\text { Melakukan request } \\
\text { dengan command /cpu }\end{array}$ & $\begin{array}{l}\text { Tampil notifikasi lama mikrotik menyala, } \\
\text { kinerja cpu mikrotik, total space ram serta } \\
\text { space ram yang digunakan dan total space } \\
\text { penyimpanan dan total space } \\
\text { penyimpanan yang digunakan }\end{array}$ & Berhasil \\
\hline 2 & $\begin{array}{l}\text { Melakukan request } \\
\text { dengan command /ping }\end{array}$ & $\begin{array}{l}\text { Tampil notifikasi ping ke DNS public } \\
\text { serta time koneksi ping dan packet lost }\end{array}$ & Berhasil \\
\hline 3 & $\begin{array}{l}\text { Melakukan } \\
\text { dengan } \\
\text { /hotspot }\end{array}$ & $\begin{array}{l}\text { Tampil notifikasi jumlah user hotspot } \\
\text { yang aktif }\end{array}$ & Berhasil \\
\hline
\end{tabular}

\section{KESIMPULAN}

Penelitian ini menghasilkan simpulan dengan menggunakan bot telegram dapat mempermudah admin atau teknisi dalam mendapatkan informasi konektivitas jaringan secara realtime, dalam mendapatkan informasi user yang login dan logout kedalam jaringan dan dalam mendapatkan informasi kondisi fisik mikrotik router.

Serta saran dalam penelitian ini Sistem masih jauh dari kata sempurna diperlukan pengembangan lebih lanjut agar dapat memberikan notifikasi secara detail dan diperlukan pengembangan lebih lanjut agar dapat melakukan konfigurasi mengunakan secara jarak jauh dan fasilitas dari menu bot telegram bisa lebih diperbanyak lagi

\section{DAFTAR PUSTAKA}

Do, T. M. T., \& Gatica-Perez, D. (2013). Human interaction discovery in smartphone proximity networks. Proceedings of the International Symposium on Wearable Computers, San Francisco.

Hardana \& Irvantino, I. (2014). Konfigurasi Routerboard Mikrotik RB-750. Yogyakarta: Andi Offset.

Sommerville, I. (2011). Software Engineering 9. (M. Horton, Ed.) (9th ed). Boylston Street, Suite 900, Boston, Massachusetts 02116: Pearson Education, Inc.

Telegram Team-1. (2015). Telegram Bot API. Tersedia pada: https://core.telegram.org/Bots/api (Diakses 20 Maret 2019).

Telegram Team-2. (2015). Telegram Bot. Tersedia pada: https://telegram.org/faq\#q-whatis-telegram-whatdo-i-do-her (Diakses 20 Maret 2019). 